\title{
Reports of EASD Study Groups 1986/1987
}

\section{Diabetic Pregnancy Study Group (DPSG)}

The aims of the Diabetic Pregnancy Study Group (DPSG) of the EASD are to improve the care of pregnant diabetics patients and their offspring by fostering research, treatment and education on the subject of diabetic pregnancy.

The group is affiliated to the European Association for the Study of Diabetes and it holds one scientific meeting each year, normally either immediately before or after the EASD-meeting. The group consists currently of 29 ordinary members who basically are elected in order to secure a multi-disciplinary nature of the group and the desirability of a broad European representation. The group has also 10 honorary members who have the full rights of participation in the scientific meetings of the group but not the rights to invite a guest or to vote at the business meetings of the group. The present version of the group's Constitution, which was amended in 1983, will be formally reconsidered in 1989 in the light of experience gained since 1983.

The annual scientific meetings are normally attended by the great majority of the members, and the meetings are open to anyone else interested in diabetic pregnancy at the discretion of the Board and the co-opted organiser. The total number of attendants will, however, not normally exceed 60 persons. The reason for this limitation in the number of participants is a strong wish to preserve the workshop atmosphere that has proven to be very creative in the past.

The 1986 DPSG meeting was held in Catania, Sicily hosted by Professor Sebastiano Grasso. The meeting focused upon fetal formation and anomalies, placental morphology and function, influence of diabetic late complications on the outcome of diabetic pregnancy, gestational diabetes and animal studies relevant to diabetic pregnancy.

The 1987 DPSG meeting will be held in Berlin, GDR during 12-15 September 1987. The meeting will be attended by about 60 persons; the scientific programme comprises 27 oral presentations. The main theme this year is Gestational Diabetes Mellitus; this subject is going to be extensively explored by a wide range of presentations dealing with, e.g., definition, screening, diagnosis, genetics, metabolic features and treatment. The second main theme is the Effect of Diabetes on the Fetal Placental Unit and the Offspring, in which subjects such as the influence of maternal diabetes on transfer of glucose to the fetus and the effect of protein deprivation during pregnancy on the fetal endocrine pancreas will be discussed. The third theme, which has been designated New Advances, will highlight interesting new results that do not naturally fit into the two previously mentioned sections. The meeting will, as usual, also comprise the annual Jorgen Pedersen Memorial Lecture, which this year will be given by Professor David Pyke, who has chosen the title "Diabetic Pregnancy - a historical survey" for his lecture.

The Board of the DPSG currently consist of Claus Kühl, MD, Chairman, Tom Lind, MD, Chairman-elect, and Francoise SodoyezGoffaux, MD.

Claus Kühl, MD (Chairman Diabetic Pregnancy Study Group)
Artificial Insulin Delivery Systems, Pancreas and Islet Transplantation Study Group (AIDSPIT)

This Study Group held, as its main activity, its sixth workshop on 2-3 February 1987 in Igls, Austria. The workshop opened with reports on the current status of islet transplantation and pancreatic organ transplantation. Islet transplantations were reported to be still largely unsuccessful in man, though there have been some reported successes with autotransplantation, and a limited number of successful cases in a large series from China. It is still unclear that transplantation of fetal islets is more promising than islets derived from adult pancreas, and fundamental questions as to ischaemia time, islet mass impurity, site of graft, and immunosuppression still remain to be addressed. By contrast, pancreatic transplantation was reported to have a continually improving success rate in the few centres that were able to do large numbers of grafts. Success seems to be independent of the technique used for coping with the exocrine secretion, a graft function is better when performed in conjunction with kidney transplantation, though there may be increased risk to the patient. Graft function rates at 12 months are now being reported up to $75 \%$, when using triple immunosuppression. Dr. Pipeleers discussed the fact as necessary for increasing islet availability for transplantation in man, where he estimated that perhaps 50 million islet B cells were needed per graft. This would imply yields of $50 \%$, while current techniques were only achieving around $20 \%$. Dr. C Barker commented on the problem of rejection versus a recurrence of insulinitis after grafting, pointing to the phenomenon of "rejection" occurring experimentally even after induction of immune tolerance. Histological methods remain poor for differentiating between these events. Attention was, however, turning to possibilities for avoiding recurrence of autoimmune insulinitis, though ideas are only at an early stage. In the free communications session Dr. Tyden, on reporting metabolic studies with segmental grafts (survival now $74 \%$ at 1 year), pointed out that many of the recipients still showed impaired glucose tolerance, and some indeed were diagnostically diabetic by definition. Many were hyperinsulinaemic. He thought that cyclosporin was at least partly responsible for the glucose intolerance. In the series of patients transplanted in Munich, Dr. Ulbig reported uncontrolled but fairly dramatic results in terms of improvement of already present proliferative retinopathy. In particular it seemed surprising that there was a remarkable reduction in the rate of vitreous haemorrhage following successful pancreatic transplantation. The free communications session was also devoted to attempts at transplantation of fetal islets in man, and to modification of the immunogenicity of transplanted islets. One reported approach to this was the use of anti-DR monoclonal antibodies, claimed to produce the disappearance of intra-islet dentritic and macrophage elements.

A further approach to islet transplantation is micro encapsulation of islets, so that they do not excite immune reaction. Dr. Chicheportiche from Paris reported, however, that there were problems of diffusion of glucose and insulin through the recently suggested alginate-polylysine membrane.

A poster exhibition and poster discussion session addressed various questions of artificial insulin delivery. Sulphated insulins are 
coming under more detailed scrutiny, there apparently being a degree of sulphation which retains significant potency whilst still giving a lot of protection against aggregation. Meanwhile, Dr. Micossi reported on the loss of potency, and induction of insulin antibodies, with the use of intraperitoneal delivered glycerol-insulins. A number of posters continued to remark on the problems of reactions to intraperitoneal placed catheters when used for insulin delivery. Reports from Paris and Karlsburg reported the earliest results from the WHO trial of subcutaneous insulin infusion. A number of posters dealt with the new insulin pen injectors, the first reports of successful insulin delivery by patients for insulin suspensions.

The second day of the meeting opened with Dr. Bending reviewing the many studies now published of the relationship between intensive insulin infusion therapy and the progression of retinopathy and early nephropathy. It was now apparent that studies were beginning to agree that longer periods of very tight control under research circumstances and progression of tissue damage might be arrested. It is unclear, however, that this can be applied to the general clinical situation. Dr. Pfeiffer reviewed the events of the recent Reisensburg symposium with respect to glucose sensors, where there is definite progress in the technology, though without any immediate promise of devices of clinical utility. Dr. Kerner later reported on one such amperometric steel electrode, with good linearity, and low oxygen dependency, though still with a high temperature dependency and rather sensitive to uric acid and ascorbic acid.

In a session on technical developments, representatives of industry discussed the future for devices for blood glucose measurement, and pen injectors for insulin. One interesting possibility with the latter was to use a multiply-perforated needle offering the possibility that the early tissue diffusion phase of subcutaneous absorption could be shortened, bringing the profile of soluble insulin closer to that found physiologically after meals. Dr.Ziegler reported from Toul that experience of memory meters had revealed the degree of under- and over-reporting previously recorded in the USA, the degree of fabrication correlating glycosylated haemoglobin estimation. A more complicated patient management system was discussed by Dr.Spiker, the system requiring patients to record meal times and doses as well as exercise on their portable meters. At this early stage this small group of patients appeared to be willing to enter information on the basis of 3 to 4 days per week, but it was noted that not many would carry the instrument around with them. Dr. Howorka reported an extension of the system previously used for basal/bolus delivery. This modified estimates based on weight calorie and carbohydrate intake, according to current insulin doses and level of control.

The final session of the meeting dealt with immune modulation, in respect of the treatment of newly diagnosed Type 1 (insulin-dependent) diabetes. Current studies do quite strongly suggest that cyclosporin A does have a useful effect in this respect, but unfortunately the results from recently completed multi-centre studies were not available at the meeting. One new possibility canvassed was that the agent called Ciamexone might be useful in this respect, and it did appear experimentally that this drug might be less toxic than cyclosporin to pancreatic islets. The precise site of action of Ciamexone is unclear, though it appears to be without major effect on the lymphocyte $\mathrm{T}$ cell function. The meeting did not feel that, with the present state of knowledge with regard to these toxic drugs, it could be recommended that they should enter general usage at the present.

At the general meeting of the Study Group, attended by EASD members, it was felt that the workshop should continue on an annual basis, though the number of good quality abstracts relating to artificial insulin delivery had diminished. Nevertheless, through 270 registrants at the meeting, the financial state of the Study Group remains sound. In general it was felt a good idea to keep the meeting in Igls, to provide continuity of identity, and support was given for publication of a report of the meeting in Diabetologia, if possible, and for the Study Group to make recommendations as to the form and future of relevant research, and future clinical policy if the EASD council would allow this. Dr. Waldhäusl and Dr. Home resigned from the organising committee as previously announced.
Dr.G. Pozza was elected President, Dr. T.Deckert Vice-President, and Dr.Bratusch-Marrain took up his post as secretary. The next meeting of the study group will be on 1-2 February 1988. Dr. P.D. Home (9 February 1987)

\section{European Diabetes Epidemiology Study Group (EDESG)}

Addresses for Correspondence

Dr. Eveline Eschwege, INSERM, Unité de Recherches Statistiques, 16. Avenue Paul-Vaillant-Couturier, F-94807 Villejuif Cedex, France Dr. G. Sartor, Department of Internal Medicine, University Hospital of Lund, S-22185 Lund, Sweden

\section{Officers}

Chairman: Dr. E. Eschwege - Villejuif Cedex

Vice-Chairman: Professor Dr. D. Michaelis -

Karlsburg

Secretary: Dr. G. Sartor - Lund

Retires: 1990

Committee Members

Professor Dr. K. Pyorälä - Kuopio

Professor Dr. G.Crepaldi - Padova

Dr. Cz. Arnold - Budapest

Retires: 1990

Retires: 1990

Total Membership in Study Group: 53

Last Meeting: 22nd Annual Meeting of the European Diabetes Epidemiology Study Group, Oxford, England, 12-15 April 1987

\section{Summary of the Meeting}

During the last Meeting, which was organized by Dr. J.Mann at Lady Margaret Hall in Oxford, 36 scientific papers and study designs, respectively, were presented dealing with the following topics: effect of low dietary protein intake on diabetic nephropathy; risk determinants of micro- and macroangiopathy, of excess mortality in diabetes mellitus; impact of obesity on diabetes incidence and mortality.

\section{Main results}

1. Unequivocal positive effect of low protein diet $(40 \mathrm{~g} /$ day) on proteinurea, albuminurea, IgG-excretion, progressive reduction of glomerular filtration rate in diabetic nephropathy.

2. Significant higher prevalence of hypertension in Type 2 (non-insulin-dependent) diabetic patients and Type 1 (insulin-dependent) diabetic patients than in the age and sex matched non-diabetic population.

3. Positive correlation between hypertension and coronary heart disease as well as circulatory mortality in diabetic patients.

4. Recognition of obesity (up to BMI <31) in association with an increased waist-hip-ratio as risk factor for diabetes incidence, but not for survival time after diabetes onset and circulatory disease mortality.

5. Confirmation of diabetes duration, degree of metabolic control and systolic blood pressure as determining risk variables for the development and progression of diabetic retinopathy.

Next meeting:23nd Annual Meeting of EDESG, May 1988, Geneva, Switzerland or Düsseldorf, FRG. Proposed topics: diabetes in the elderly; epidemiology of neuropathy and nephropathy; mortality in diabetic patients. Details available from: Dr. G. Sartor, Department of Internal Medicine, University Hospital, S-22185 Lund, Sweden

Professor D. Michaelis, MD (Past Secretary)

\section{European Diabetic Nephropathy Study Group (EDNSG)}

The European Diabetic Nephropathy Study Group (EDNSG) has been established with the aim of assembling researchers interested in diabetic renal disease in order to study epidemiology, pathology, pathophysiology and treatment of this complication of diabetes mellitus. The ultimate goal of the Group is to prevent the appearance or the development of kidney damage and to search for the best treatment of this condition in diabetic patients.

The first meeting of the EDNSG will be in Pisa, Italy, on 22-23 April 1988; the topic to be discussed will be: Blood Pressure 
and Diabetic Nephropathy: Pathogenesis and Treatment. The Organising Committee will include Drs. Romano Nosadini and Umberto Di Mario and Professor Renzo Navalesi.

The next meeting in the spring of 1989 is planned to take place in Aarhus, Denmark.

Dr. Giancarlo Viberti (Chairman, EDNSG)

\section{Diabetes Education Study Group}

The aim of the Study Group is to improve the quality of life of the diabetic patient through the development and evaluation of educational programmes designed to foster independence for the patient, to improve the quality of metabolic control, to emphasize the importance of prevention and early recognition of the disease and to encourage relevant research.

The Diabetes Education Study Group (DESG) has been able to continue its activities thanks to the generous financial support of the Laboratoires Servier of France since the begining of DESG in 1979. This sponsorship is greatly appreciated.

The 1986-1987 activities were the following:

\section{Workshops}

a) The 3rd and 4th Teaching Letter Workshop. Two Workshops were held in Athens, Greece: one in December 1986 and one in April 1987.

The Teaching Letters were drafted by a group of 58 physicians, nurses, dietitians, educators and psychologists coming from different European countries. During the 3rd Workshop a new set of four Teaching Letters were prepared with the following subjects: "Foot care"; "Counselling on complications"; "Approaching the parents of a diabetic child"; "Hypoglycaemia". The format of the teaching letter is A4 and runs to four pages. The Letters of the 3rd Workshop have been printed and distribution was started in April 1987. During the 4th Workshop five new Teaching Letters have been prepared and the subjects are: "Evaluating diabetes education"; "Teaching the woman with diabetes about preparing conception, pregnancy and delivery"; "Educating the elderly diabetic patient"; "Nutrition for the child and adolescent with diabetes mellitus"; "Continuing and reinforcing patient education". These Letters are in the process of being edited and will be distributed before the Annual EASD Meeting in September 1987. Up to now the first 11 Teaching Letters have been translated into 9 languages. The aim of these letters is to provide guidelines and motivate health care providers involved in diabetes care to improve their educational skills with patients.

b) Workshops at the national level. National branches of the DESG have become increasingly active for the training of physicians, nurses and dietitians. In 1986-1987 in the United Kingdom, under the guidance of Dr. John Day, two primary, one follow up (involving 40 people each) and one special workshop (for 60 people) took place. The latter was held to consider the need for the design and financing of special diabetes education and care centres.

2. Symposia

a) A Symposium under the auspices of the DESG was held in October 1986 in the Netherlands, organised by Dr. Henk E. Pelser, on Diabetic Patients as Educators in Diabetes. The Symposium was attended by 66 participants from different countries including diabetologists, nurses, social workers, health educators and dietitians. A majority of 38 were diabetic patients. The objectives of this meeting were: (i) to have diabetic patients from different European countries present their experiences as "educators in diabetes"; (ii) to exchange experiences with health care professionals about the possible contribution diabetic patients can make to diabetes education. The proceedings of this Symposium will be prepared for publication. A preliminary report by Dr. Henk Pelser has been published in the DESG-Newsletter.

b) A symposium was held in March 1987 in Baden under the auspices of the DESG on Functional near-normoglycaemic insulin substitution by multiple injections or CSII. It was organised under the responsibility of Dr.Kinga Howorka, Dr. Helga Grillmayr and Dr. Herwig Thoma. The 52 participants registered were from different European countries. The objective of this symposium was to present to diabetic educators a specific educational approach which has been developed in Vienna during the last four years, given the name "Functional near-normoglycaemic insulin substitution". Contributions of invited speakers were made on:

Insulin production rate of healthy man as the basis for functional insulin substitution (Prof. Werner Waldhäusl, Vienna).

How to listen better to patients - new concepts of teaching, learning and education and their application to the patient-doctor cooperation in the treatment of diabetes mellitus (Dr. Henk Pelser, Amsterdam).

The history and the contemporary state of patient education in Type 1 (insulin-dependent) diabetes mellitus (Prof. Dr. Michael Berger, Düsseldorf).

Group dynamics of the structured and systematic patient education within the institution (Dr. Walter Milowiz, Vienna).

\section{DESG - Newsletter}

It was thought that the Executive Committee of the DESG should have a closer communication with its members of the Study Group giving information about recent activities, future projects, as well as any other valuable information related to diabetic patient education. With this in mind the first issue of the DESG-Newsletter was published in January 1987 and distributed to all its members.

\section{Change of the offices of the Executive Committee}

On the termination of his term of office as president of DESG in 1985 of Dr. Jean-Philippe Assal I would like, on behalf of the members of DESG, to thank him for his great contribution to the care of those with diabetes by his foresight, originality and enthusiasm in the initiation and development of the activities of the DESG, which are now bearing fruit throughout Europe.

My great appreciation goes also to Dr. Henk Pelser whose term of office as Vice-President of the Diabetes Education Study Group ended in 1986 and was replaced by Dr. John Day. I would like also to thank the members of the Executive and General Committee of DESG for their contribution to the activities of the DESG. John G. Alivisatos (President, DESG) 